\title{
Violencia de género ocasional: Un análisis de las penas ejecutadas
}

Manuscrito recibido el 16 de febrero de 2009

\author{
Lorena Antón García \\ Universidad Autónoma de Barcelona
}

\author{
Elena Larrauri Pijoan \\ Universidad Pompeu Fabra
}

\begin{abstract}
RESUMEN
En el año 2003 se han aprobado diversas leyes en materia de violencia doméstica que han supuesto la elevación a delito de las conductas de violencia ocasional y una agravación general de las penas en este ámbito. La investigación empírica que se ha llevado a cabo, relativa al maltrato ocasional en el ámbito de la pareja, pretende conocer cómo este aumento de penas ha sido aplicado por los jueces. Para ello, se ha realizado un análisis cuantitativo de las sentencias condenatorias por el delito mencionado y de los autos de ejecución correspondientes a cada una de esas sentencias, que ha servido para conocer cuándo los jueces optan por la pena de prisión y cuándo por el uso del trabajo en beneficio a la comunidad para el maltrato ocasional en la pareja; cuáles son las penas definitivas que efectivamente se cumplen; y cuál es el porcentaje de aplicación de las reglas de conducta, concretamente, la obligación de realizar programas formativos o de tratamiento como condición para la concesión de la suspensión de la pena de prisión.
\end{abstract}

Palabras clave: violencia de género, maltrato ocasional, penas, prisión, programas formativos

\section{ABSTRACT}

Since 2003 Spain has witnessed the creation of new crimes and the enhancement of some penalties relating to domestic violence, and more specifically to occasional gender violence. Our research tries to find out the impact of these legal reforms analyzing the penalties that judges are effectively sentencing. Through an empirical quantitative research from sentences of occasional gender violence we try to find out when imprisonment is imposed as a punishment, whether the sentence is or not suspended, when additional rules like the obligation to attend an educational programme are effectively enforced and finally when a community order sentence is being served.

Key words: gender violence, occasional violence, sanctions, prison, educational programme 


\section{Introducción}

En los últimos años la presión social y las críticas por parte de grupos feministas (Instituto de la Mujer 1990; Falcón 1991) y de la doctrina (Medina 2002: 31 y ss.) han llevado al legislador a preocuparse y prestar más atención al tema de la violencia doméstica, en particular a la violencia contra la mujer en las relaciones de pareja.

Desde 1989, año en el que por primera vez se tratan como delito los malos tratos habituales en el ámbito familiar, se han aprobado varias modificaciones legales. Las últimas reformas, siempre de carácter más punitivo, se han realizado justificándose más o menos explícitamente en un trasfondo que cuestionaba que la violencia contra la mujer se estuviese realmente castigando por el sistema penal.

El objeto central de este trabajo es conocer qué penas se imponen y qué penas se cumplen por la comisión de un delito de maltrato ocasional cuando éste se produce en el ámbito de la pareja. Para ello se toman en cuenta las dos reformas básicas: la LO 11/2003, de 29 de septiembre, de medidas concretas en materia de seguridad ciudadana, violencia doméstica e integración social de los extranjeros (en adelante LO 11/2003) y la LO 1/2004, de 28 de diciembre, de medidas de protección integral contra la violencia de género (en adelante Ley Integral).

Nos hemos centrado en estas dos leyes porque son las que, a nuestro juicio, producen los dos cambios fundamentales en materia de maltrato ocasional. Hasta el año 2003, el maltrato ocasional era constitutivo de falta, estaba regulado en el art. 617.2 CP y castigado con la pena de arresto de fin de semana o multa. Con la LO 11/2003 el maltrato ocasional en el ámbito doméstico pasa a considerarse delito y a regularse en el art. $153 \mathrm{CP}^{1}$, castigándose con pena de prisión de tres meses a un año o trabajo en beneficio de la comunidad (en adelante TBC) de 31 a 80 días.

\footnotetext{
${ }^{1}$ El que por cualquier medio o procedimiento causara a otro menoscabo psíquico o una lesión no definidos como delito en este Código, o golpeara o maltratara de obra a otro sin causarle lesión, o amenazara a otro de modo leve con armas y otros instrumentos peligrosos, cuando en todos estos casos el ofendido fuera alguna de las personas a las que se refiere el artículo 173.2 será castigado con la pena de prisión de tres meses a un año o trabajos en benefício de la comunidad de 31 a 80 días (...). (Art. 153 CP, tras la reforma operada por la LO 11/2003).
}

Revista Española de Investigación Criminológica

Artículo 2, Número 7 (2009) $\quad$ www.criminología.net

ISSN: $1696-9219$ 
Por su parte, la Ley Integral, como puede verse más en detalle en la Tabla 1, aumenta las penas y pasa a castigar de forma más grave los actos de maltrato ocasional en los que el sujeto pasivo es la mujer pareja o ex pareja, en cuyo caso la pena de prisión será de seis meses a un año (art. 153.1 $\mathrm{CP}^{2}$ ).

La razón principal que nos llevó a realizar este trabajo era saber en qué medida los jueces iban a aplicar la pena de prisión por la comisión de un maltrato ocasional en el ámbito de la pareja, especialmente considerando que hasta el año 2003 este comportamiento estaba castigado con multa o arresto de fin de semana y que numerosas voces se habían alzado contra la reforma de la LO 11/2003, apuntando a la desproporcionalidad de la pena de prisión para castigar estos actos de maltrato ocasional.

El segundo objetivo era saber qué penas se están cumpliendo efectivamente por la comisión de este delito. La mayor parte de investigaciones realizadas ignoran la ejecución de la pena, comprensiblemente teniendo en cuenta las enormes dificultades prácticas que este estudio conlleva. No obstante, nosotras hemos creído necesario, además de conocer en qué medida se opta por la imposición de la pena de prisión, averiguar si a la persona a la cual se le impone una pena privativa de libertad acaba realmente entrando en prisión o si ésta se suspende o sustituye.

En el caso en el que la pena fuera suspendida, queríamos averiguar y este era el tercer objetivo, si también en el ámbito de las penas no privativas de libertad se está experimentando un endurecimiento de las condiciones con las que se otorgan, tal y cómo está sucediendo en general en otros países europeos (Larrauri, 2005b).

Antes de examinar la investigación empírica desarrollada expondremos de forma sucinta las razones alegadas para justificar la reforma penal que transformó el maltrato ocasional en delito.

\footnotetext{
${ }^{2}$ El que por cualquier medio o procedimiento causare a otro menoscabo psíquico o una lesión no definidos como delito en este Código, o golpeare o maltratare de obra a otro sin causarle lesión, cuando la ofendida sea o haya sido esposa, o mujer que esté o haya estado ligada a él por una análoga relación de afectividad aun sin convivencia, o persona especialmente vulnerable que conviva con el autor, será castigado con la pena de prisión de seis meses a un año o de trabajos en beneficios de la comunidad de treinta y uno a ochenta días (...). (Art. 153.1 CP, tras la reforma operada por la LO 1/2004).
} 


\section{2. ¿Por qué se produce el cambio de falta a delito?}

Los malos tratos en el ámbito doméstico se regulan por primera vez como delito en nuestro ordenamiento tras la aprobación de la reforma 3/1989, en el art. 425 CP. Este artículo castigaba con la pena de arresto mayor los malos tratos reiterados, entendidos como violencia física habitual contra algún miembro de la familia siempre que hubiera convivencia. Cuando el maltrato era ocasional se aplicaba la falta del art. $582 \mathrm{CP}$, cuya comisión suponía la imposición de la pena de arresto menor o de multa (Ver Medina, 2002).

Hasta el año 2003 se aprueban varias reformas ${ }^{3}$ encaminadas a solventar las críticas realizadas por parte de la doctrina (Arroyo-Muñoz, 1993:145; Cuello, 1993; Cervelló, 1994:56;) y de diferentes instituciones (Defensor del Pueblo, 1998:120-124), referentes al alcance del tipo penal - defendiendo que se incluyera la violencia psíquica y que no fuera exigible la convivencia - y a la ampliación de sujetos pasivos - abogando, por ejemplo, por la extensión de la protección a las ex parejas.

En la tabla 1 pueden verse más claramente los cambios fundamentales respecto de su calificación penal y la pena prevista que las reformas aprobadas conllevaron en materia de maltrato ocasional (centrándonos en el ámbito de la pareja).

\footnotetext{
${ }^{3}$ LO 10/1995, de 23 de noviembre, del CP; LO 11/1999, de 30 de abril, de modificación del Título VIII del Libro II del CP, aprobado por LO 1/1995, de 23 de noviembre; LO 14/1999, de 9 de junio, de modificación del CP de 1995, en materia de protección a las víctimas de los malos tratos y de la LECr; LO 38/2002, de 24 de octubre, de reforma parcial de la LECr para el enjuiciamiento rápido e inmediato de determinados delitos y faltas, y de modificación del procedimiento abreviado; Ley 27/2003, de 31 de julio, reguladora de la orden de protección de las víctimas de la violencia doméstica.
}

Revista Española de Investigación Criminológica

Artículo 2, Número 7 (2009) $\quad$ www.criminología.net

ISSN: $1696-9219$ 
Tabla 1: Evolución del tratamiento legislativo de los malos tratos ocasionales en España.

\begin{tabular}{|c|c|c|c|}
\hline & \multicolumn{3}{|c|}{ MALOS TRATOS OCASIONALES } \\
\hline REFORMA & CATEGORÍA & TIPO & PENA \\
\hline LO 3/1989 & Falta (art. $585 \mathrm{CP}$ ) & $\begin{array}{l}\text { Maltrato físico a la pareja o } \\
\text { análogo con convivencia. }\end{array}$ & $\begin{array}{l}\text { Arresto menor de uno a } \\
\text { cinco días o multa de } 750 \\
\text { a } 7.500 \text { pesetas. }\end{array}$ \\
\hline LO 10/1995 & Falta (art. 617.2 CP) & $\begin{array}{l}\text { Maltrato físico a la pareja o } \\
\text { análogo con convivencia. }\end{array}$ & $\begin{array}{l}\text { Arresto de tres a seis fines } \\
\text { de semana o multa de uno } \\
\text { a dos meses. }\end{array}$ \\
\hline LO 14/1999 & Falta (art. 617.2 CP) & $\begin{array}{l}\text { Maltrato físico o psíquico a la } \\
\text { pareja, ex pareja o análogo } \\
\text { siempre que haya o haya } \\
\text { habido convivencia. }\end{array}$ & $\begin{array}{l}\text { Arresto de tres a seis fines } \\
\text { de semana o multa de uno } \\
\text { a dos meses. }\end{array}$ \\
\hline LO 11/2003 & $\begin{array}{l}\text { Delito } \\
\text { (art. 153.1 CP) }\end{array}$ & $\begin{array}{l}\text { Maltrato físico o psíquico a la } \\
\text { pareja, ex pareja o análogo } \\
\text { aún sin convivencia. }\end{array}$ & $\begin{array}{l}\text { Prisión de tres meses a un } \\
\text { año o TBC de } 31 \text { a } 80 \text { días. }\end{array}$ \\
\hline LO 15/2003 & $\begin{array}{l}\text { Delito } \\
\text { (art. 153.1 CP) }\end{array}$ & $\begin{array}{l}\text { Maltrato físico o psíquico a la } \\
\text { pareja, ex pareja o análogo } \\
\text { aún sin convivencia. }\end{array}$ & $\begin{array}{l}\text { Prisión de tres meses a un } \\
\text { año o TBC de } 31 \text { a } 80 \text { días } \\
\text { y prohibición de } \\
\text { aproximación. }\end{array}$ \\
\hline LO 1/2004 & $\begin{array}{l}\text { Delito } \\
\text { (art. 153.1 CP) }\end{array}$ & $\begin{array}{l}\text { Maltrato físico o psíquico a la } \\
\text { pareja, ex pareja o análogo } \\
\text { aún sin convivencia. (Hombre } \\
\text { agresor y víctima mujer } \\
\text { pareja, ex pareja o análogo). }\end{array}$ & $\begin{array}{l}\text { Prisión de seis meses a un } \\
\text { año o TBC de } 31 \text { a } 80 \text { días } \\
\text { y prohibición de } \\
\text { aproximación. }\end{array}$ \\
\hline
\end{tabular}

Puede observarse que a efectos de penalidad el cambio fundamental en el tratamiento jurídico de los malos tratos se produce a partir del cambio de falta a delito introducido por la reforma 11/2003, que hace posible la imposición de la pena de prisión a los malos tratos ocasionales.

La reivindicación de un cambio de categoría en materia de maltrato ocasional en el ámbito doméstico fue fruto de una discusión que alegaba a la inconveniencia del tratamiento de falta para las agresiones cometidas en el ámbito doméstico. Las razones 
que manifestaron algunos sectores políticos y doctrinales y distintos entes sociales ${ }^{4}$ para justificar el cambio de categoría fueron las siguientes:

Se consideraba que hasta el momento las sanciones impuestas eran leves, por lo que se reivindicaba la necesidad de agravar las penas reclamando el endurecimiento de las penas impuestas y una respuesta 'más eficaz y contundente desde el ámbito judicial', $\left(\right.$ Hernando $\left.^{6}\right)$. Autores como Cortés (2000: 106), Morillas (2002: 8-19), Comas (2005: 21) y Magro (2005: 237) apuntaban que las penas impuestas eran leves en relación a los hechos, afirmando que la pena privativa de libertad respetaba el principio de proporcionalidad, por lo que reivindicaban la eliminación de la falta del art. $617 \mathrm{CP}$, describiendo como "suave" la calificación jurídica de los hechos (Alberdi - Matas, 2002: 293-294).

En esta misma línea, el Consejo General del Poder Judicial, siguiendo las recomendaciones redactadas en el 'Libro blanco de la justicia', propuso eliminar las faltas y que los actos de maltrato se resolvieran, bien castigando aquellos que tuvieran 'entidad suficiente' como delito, o bien reenviando los que carecieran de gravedad a la jurisdicción civil, quedando excluidos como ilícitos penales (CGPJ, 2001: 54-57) ${ }^{7}$

También se consideraba que las sanciones aplicadas no eran adecuadas. Hasta el momento la pena impuesta de forma mayoritaria por la comisión de una falta de maltrato era la multa, criticada por la doctrina, por diferentes grupos feministas y por algunas instituciones por creer que podía suponer una afectación directa al patrimonio de las víctimas (Defensor del Pueblo, 1998: 120 y 124; CGPJ, 2001; Comas, 2002; Calvo, 2005: 35).

\footnotetext{
${ }^{4}$ Defensor del Pueblo (1998), Themis (1999, 2001 y 2003), Cortes (2000), CGPJ (2001), Delgado (2001), Alberdi Matas (2002), Comas (2002), Morillas (2002), Calvo (2003).

${ }^{5}$ Esta idea de contundencia se manifestaba ya en los objetivos fijados por el II Plan de acción contra la violencia doméstica (2001-2004).

${ }_{7}^{6}$ El Mundo, 27 de septiembre de 2002. www.elmundo.es/papel/2002/09/27/espana/1237538 imp.html

${ }^{7}$ Este Acuerdo suscita numerosas críticas, tanto por parte de los grupos feministas (Ver Themis, 2001), que están en desacuerdo con la total desaparición de las faltas ante el temor de que haya aún más impunidad, como por parte de la doctrina, que considera la propuesta de eliminar las faltas extremadamente punitiva (Medina, 2002: 450 y ss). Este último autor considera además que la propuesta es ambigua, pues crea una incertidumbre en cuanto a qué casos serán considerados como delito y cuales serán reenviados al juez civil.
}

Revista Española de Investigación Criminológica

Artículo 2, Número 7 (2009) $\quad$ www.criminología.net

ISSN: $1696-9219$ 
Además de las críticas esencialmente dirigidas a la pena de multa, se consideraba necesario el cambio de categoría a delito para que las conductas quedasen registradas y pudieran tenerse en cuenta a efectos de reincidencia (Comas, 2005: 21).

Por lo que respecta al proceso penal de faltas, se puso de manifiesto la falta de interés y de rigor en el tratamiento de las pruebas por parte de los agentes relacionados con el proceso, desde la policía hasta los jueces y el Ministerio Fiscal. Este desinterés dificultaba aún más la tarea de probar los hechos y hacía que los jueces, a pesar de encontrarse con hechos susceptibles de ser calificados de delito, los calificasen de falta y los juzgasen como tal.

El hecho de que la mayoría de los casos de malos tratos se calificaran de falta suponía además que fueran juzgados por los jueces de instrucción, favoreciendo así la absolución, ya que la estructura del juicio de faltas, que impide el sobreseimiento, es lo que probablemente propiciaba el alto numero de absoluciones, por lo que también bajo una perspectiva procesal parecía conveniente procesar los hechos como delito (Themis, 1999:89-90; Delgado, 2001; Calvo, 2004).

Por último, al ser catalogados como falta algunos estudios concluyeron que las penas en ellas previstas no cumplían con el fin de protección de las víctimas (Themis, 1999: 91) y se criticó la imposibilidad legal de imponer medidas cautelares (Comas, 2002) y órdenes de protección (Delgado, 2001; Larrauri, 2004) a los comportamientos catalogados de falta, impidiendo así garantizar la seguridad de las víctimas.

En definitiva, las reivindicaciones principales iban encaminadas a eliminar la pena de multa y a exigir una orden de protección para las víctimas. Todo ello, unido a las deficiencias que evidenciaba el proceso por falta, hizo que una parte de la doctrina considerase más adecuado el tratamiento de los malos tratos ocasionales como delito.

Esta discusión sin duda favoreció la aprobación de la LO 11/2003 y la consiguiente regulación del maltrato ocasional como delito. Éste quedó regulado en el art. $153 \mathrm{CP}$, dentro del Título III, del Libro II del Código Penal, relativo a las lesiones. 
La aprobación de esta ley suscitó rápidamente desacuerdos dentro del ámbito doctrinal y judicial. Una parte de la doctrina consideró que las penas impuestas eran desproporcionadas y excesivas y que esta modificación era difícilmente justificable en términos de proporcionalidad, adecuación y necesidad (Laurenzo, 2003: 9-11; Asúa, 2004: 222-226; Benítez, 2004: 96-98).

Además, se plantearon dos cuestiones de inconstitucionalidad por considerar que el nuevo art. $153 \mathrm{CP}$ era contrario al principio de legalidad penal y de proporcionalidad sancionadora. El Tribunal Constitucional resolvió estas cuestiones desestimándolas por considerarlas 'notoriamente infundadas' (ATC 233/2004, de 7 de junio de 2004 y ATC 332/2005, de 13 de septiembre de 2005), manifestando que:

el legislador ha combinado esta ampliación con la puesta a disposición del órgano judicial de resortes necesarios, como lo es la alternativa entre la pena de prisión o de trabajos en beneficio de la comunidad, a la hora de determinar y adecuar la pena correspondiente en concreto a cada forma de manifestación de esas conductas de violencia doméstica; esto es, para atemperar la sanción penal a la entidad de las conductas de violencia doméstica, que si bien en unas ocasiones pueden revestir menor trascendencia que en otras en atención al bien jurídico protegido, no por ello deben quedar impunes. (ATC 233-2004)

Lo que el Tribunal Constitucional no aclaró, como bien observa Peñaranda (2008), es si la aplicación de la pena de prisión a las conductas, que el propio TC denominó de 'menor trascendencia', contraría el principio de proporcionalidad, que es exactamente lo que las cuestiones de constitucionalidad planteaban. A la vista de nuestra investigación, que muestra lo escasamente que se aplicó la pena alternativa de trabajos en beneficio a la comunidad bajo esta primera ley, no puede por menos que temerse que el principio de proporcionalidad fuera infringido en su aplicación.

La segunda reforma relevante para nuestra investigación es la introducida por la Ley integral, que como ya hemos mencionado anteriormente, aumenta la pena cuando la víctima es la mujer pareja o ex pareja. Esta ley estableció además que si la pena de prisión se suspende, no solo quedará condicionada de forma obligatoria a las 
prohibiciones de no acudir a determinados lugares y de acercarse a la víctima ${ }^{8}$, sino también a la obligación de realizar programas formativos o de tratamiento (art. $83 \mathrm{CP}$ ).

Esta Ley Integral, provocó también una apasionada discusión entre sus partidarios y los que la consideraban inconstitucional por atentar contra derechos básicos constitucionales como el principio de igualdad $^{9}$. Pero lo que se desconocía era el impacto real, por lo que se refiere a las penas del maltrato ocasional, a la agravación de las penas que tantas discusiones teóricas había suscitado.

Una vez expuesto el contexto teórico en el cual se producen las reformas legales que pretenden, en primer lugar, permitir la imposición de la pena de prisión a los malos tratos ocasionales, en segundo lugar, agravar la pena cuando la víctima es la mujer pareja, y finalmente, aumentar las condiciones impuestas en el caso en que se suspenda la pena de prisión, pasamos a exponer la investigación empírica desarrollada para conocer qué penas se imponen y se cumplen por la comisión de un delito de maltrato ocasional en la pareja.

\section{Estudio empírico}

La investigación consiste en un análisis cuantitativo de las sentencias condenatorias dictadas entre el 1 de octubre de 2003 y el 31 de diciembre de 2006, por los juzgados de Barcelona, por un delito de maltrato ocasional cometido por el hombre o la mujer pareja $^{10}$, regulado en el art. $153 \mathrm{CP}$.

Recordemos que estas sentencias están dictadas bajo la aplicación de la LO 11/2003, por la que se aprueba el cambio de categoría de falta a delito, y de la Ley Integral, que castiga con una pena mayor cuando la víctima es la mujer pareja o ex pareja e impone de forma obligatoria la asistencia a un programa formativo cuando la pena de prisión se suspende.

\footnotetext{
${ }^{8}$ Imposición que había realizado la LO 15/2003.

${ }^{9}$ Esta cuestión ha sido resuelta por el Tribunal Constitucional en su sentencia 59/2008, de 14 de mayo de 2008, en la que se declara el contenido del art. 153.1 CP dado por la Ley Integral, de conformidad con la Constitución Española. Véase comentario más amplio en Larrauri (2009).

${ }^{10}$ En este estudio hemos tenido en cuenta todos los casos de maltrato ocasional en los que la víctima era uno de los miembros de la pareja, si bien, conviene mencionar que las mujeres son víctimas en un $93,6 \%$ de los casos analizados.
}

Revista Española de Investigación Criminológica

Artículo 2, Número 7 (2009) $\quad$ www.criminología.net

ISSN: $1696-9219$ 
Para entender el desarrollo de esta investigación es necesario exponer los tres momentos clave. El primero, es la selección de sentencias condenatorias por el delito de malos tratos ocasionales en el ámbito de la pareja y el estudio de las mismas. El segundo, es el análisis de los autos de ejecución correspondientes a cada una de las sentencias. Y por último, el tratamiento de los datos y la obtención de los resultados.

La particularidad de este estudio es que hemos tenido en cuenta, a la hora de hablar de las penas, no las penas impuestas, sino las penas definitivas, esto es, las que efectivamente se cumplen por la comisión de este delito, datos de los que hasta el momento no se disponía en nuestro país. Hemos considerado imprescindible no detenernos en el análisis de las sentencias condenatorias y acudir a los juzgados de ejecución para poder presentar datos de condenas ejecutadas y dar una visión de las penas que efectivamente se cumplen por maltrato, con el fin de poder conocer el impacto punitivo de las reformas estudiadas.

\subsection{Objetivos}

Los tres objetivos básicos de esta investigación son:

- Conocer las penas que imponen los jueces por la comisión de un delito de malos tratos en el ámbito de la pareja. Nos interesa saber si se ha cumplido el propósito del legislador y las pretensiones de una parte de la doctrina de endurecer las penas a través de la imposición de la pena de prisión, o bien si los jueces han 'neutralizado' esta posibilidad $^{11}$.

- Saber cuáles son las penas definitivas, es decir, el porcentaje de penas de prisión efectivamente cumplidas y el porcentaje de suspensiones y de sustituciones. Averiguar además, en qué medida se sigue aplicando la multa por vía de la sustitución de la pena de prisión.

- Por último, averiguar qué tipo de suspensión se concede, es decir, en qué porcentaje se hace uso de la suspensión ordinaria (con la única condición de no volver a delinquir) y de la suspensión con reglas de conducta (con la condición de cumplir alguna de las reglas reguladas en el art. $83 \mathrm{CP}$ ). Especialmente se quiere analizar si los

\footnotetext{
${ }^{11}$ Recordemos que el Tribunal Constitucional (ATC 233-2004, de 7 de junio y ATC 332-2005, de 13 de septiembre), justificaba la proporcionalidad del art. $153 \mathrm{CP}$ argumentando que al existir la posibilidad de aplicar el TBC como pena principal opcional, la pena privativa de libertad se reservaría para los casos más graves de maltrato.
}

Revista Española de Investigación Criminológica

Artículo 2, Número 7 (2009) $\quad$ www.criminología.net

ISSN: $1696-9219$ 
jueces de ejecución imponen la obligación de realizar programas formativos o de tratamiento cuando conceden la suspensión.

En la medida de lo posible hemos intentado comparar los resultados de nuestra investigación con la situación anterior a la LO 11/2003, basándonos en otros estudios llevados a cabo en nuestro país (Themis, 1999, 2001 y 2003; Calvo, 2005; Instituto de la Mujer, 2006). Debe advertirse no obstante, que los estudios anteriores extraen sus conclusiones exclusivamente de las sentencias impuestas y no de las penas definitivas, por lo que las comparaciones deben realizarse con suma cautela.

\subsection{Método}

Para la consecución de los objetivos mencionados en el punto anterior hemos realizado un análisis cuantitativo de las sentencias condenatorias dictadas por los juzgados de lo penal, de instrucción y de violencia sobre la mujer de Barcelona. Dividimos el estudio en dos partes, en primer lugar, llevamos a cabo el análisis de las sentencias dictadas entre el 1 de octubre de 2003 y el 28 de junio de 2005, bajo la aplicación de la LO 11/2003. En segundo lugar, analizamos las sentencias dictadas entre el 1 de julio de 2005 y el 31 de diciembre de 2006, bajo la aplicación de la Ley Integral (LO 1/2004).

Partimos de una base de 1.326 sentencias por violencia doméstica, de las cuales 836 sentencias se referían a maltrato ocasional en el ámbito de la pareja. Seleccionamos las sentencias condenatorias, un total de 600 , de las cuales 273 correspondían a la primera parte del estudio y las 327 restantes a la segunda parte.

Para el análisis de las sentencias tuvimos en cuenta los recursos a la Audiencia de Barcelona, la cual absolvió en 9 casos referidos a la primera parte y en 22 casos referidos a la segunda. Además, en la segunda parte de nuestra investigación, la Audiencia resolvió 3 recursos por sentencia absolutoria condenando al imputado por un delito de maltrato ocasional en el ámbito de la pareja. Esto da un resultado de 264 sentencias referidas a la primera parte y 308 sentencias referidas a la segunda, un total de 572 sentencias condenatorias. 
En estas 572 sentencias analizadas se ha condenado a 590 personas, teniendo en cuenta las sentencias en las que se ha dictado condena mutua. Analizamos, por lo tanto, todos los datos correspondientes a las 590 personas condenadas por un delito del art. $153 \mathrm{CP}$ en el ámbito de la pareja, de las cuales 276 pertenecen a la primera parte del estudio y 314 a la segunda ${ }^{12}$.

Una vez extraídas las variables más relevantes, como las referidas a los datos de la persona condenada y a la pena impuesta en sentencia, acudimos a los juzgados de ejecución, donde analizamos los autos de ejecución correspondientes a cada una de las sentencias, en los que se recoge la pena definitiva que finalmente se va a cumplir, esto es, si se ha impuesto una pena de prisión, en el auto de ejecución se indica si el condenado va a cumplir la pena de prisión, o si por el contrario ésta se suspende o se sustituye.

\section{Resultados}

\subsection{Penas impuestas}

Uno de los objetivos de la investigación era conocer las penas impuestas por la comisión del delito de maltrato ocasional en el ámbito de la pareja para saber en qué porcentaje los jueces imponen la pena de prisión.

Antes de la reforma de 2003, por la comisión de este delito estaba prevista la posibilidad de aplicar la pena de arresto de fin de semana o de multa, y en un $85 \%$ de los casos se imponía la pena de multa (Calvo, 2004:116) ${ }^{13}$.

En el siguiente gráfico podemos observar en qué medida se hace uso de la pena de prisión y del TBC una vez entran en vigor la LO 11/2003, que permite por primera vez la imposición de una pena de prisión, y la Ley Integral.

\footnotetext{
${ }^{12}$ De estas 590 personas condenadas, en el momento de finalizar el estudio, a 39 aún no se les había ejecutado la pena ( 5 referidas a la primera parte y 34 referidas a la segunda), por lo que en alguno de los resultados presentados no se ha tenido en cuenta la población total, sino los 551 expedientes que ya están ejecutados.

${ }^{13}$ El estudio llevado a cabo por Calvo hace referencia a las penas aplicadas durante el año 2000 en Aragón por la comisión de delitos o faltas en el ámbito de la pareja. El hecho de que Calvo no se centre únicamente en el maltrato ocasional en la pareja, tal y como ocurre en nuestro estudio, hace imposible la comparación de los resultados de su estudio con los obtenidos en nuestra investigación, si bien, sus datos pueden servirnos para ver la gran aplicación de la pena de multa en los casos de violencia ocasional e incluso habitual, siendo sólo el $15 \%$ condenado a penas privativas de libertad de arresto de fin de semana y pena de prisión.
}

Revista Española de Investigación Criminológica

Artículo 2, Número 7 (2009) $\quad$ www.criminología.net

ISSN: $1696-9219$ 


\section{Gráfico 1: Penas impuestas}

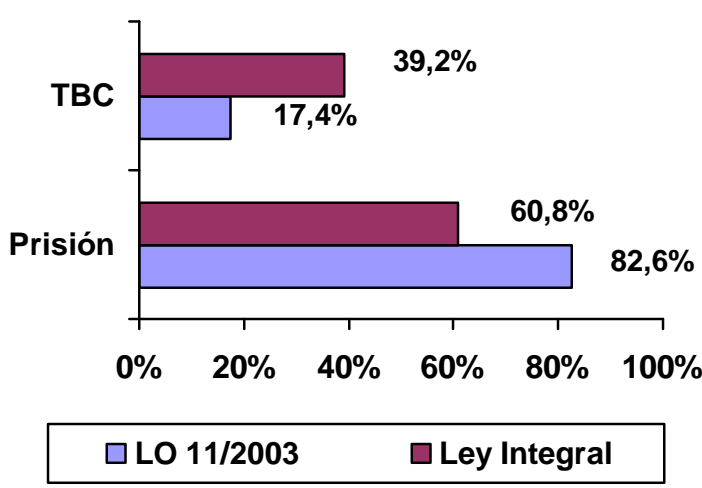

Fuente: Elaboración propia a partir de los datos obtenidos en nuestro estudio ${ }^{14}$

Según nuestro estudio, en aplicación de la LO 11/2003, los jueces optan por la pena privativa de libertad en un $82,6 \%$ de los casos. Puede observarse, en consecuencia, que dicha ley consiguió su objetivo de castigar los comportamientos que antes eran falta con la pena de prisión y, contrariamente a las expectativas del TC, otorgó un papel muy residual a la pena alternativa de trabajo en beneficio de la comunidad.

La imposición de la pena de prisión se reduce a un $60,8 \%$ en la segunda fase, esto es, bajo la aplicación de la Ley Integral. Los motivos por los cuales ello sucede no son evidentes, pero baste por ahora realzar la paradoja de un descenso de las penas de prisión en aplicación de una ley que, en un principio, pretende aumentar la severidad penal de la respuesta a los comportamientos de violencia de género ocasional.

En un segundo sentido, sí podría afirmarse que la ley consigue sus objetivos de aumentar la severidad penal. Esto es, si bien existe un $21,8 \%$ menos de condenas a prisión, es cierto que respecto al tiempo de condena de prisión impuesta, con la LO 11/2003 la pena media es de 6 meses y 2 días, y con la Ley Integral de 7 meses y 27 días.

En lo que respecta al uso del trabajo en beneficio de la comunidad, se puede observar que éste pasa de imponerse un $17,4 \%$ con la LO 11/2003, a un 39,2\% bajo la Ley Integral.

\footnotetext{
${ }^{14}$ Todos los datos mostrados en los gráficos y tablas de este artículo, excepto indicación contraria, han sido extraídos del estudio empírico realizado.
} 


\subsection{Ejecución de la pena de prisión}

En cuanto a la ejecución de la pena de prisión - en qué medida se cumple la pena de prisión inicialmente impuesta y en qué medida ésta se suspende o se sustituye podemos observar los resultados obtenidos en el siguiente gráfico.

Gráfico 2: Porcentaje de suspensiones, sustituciones y ejecuciones de penas privativas de libertad respecto del total de condenados a prisión

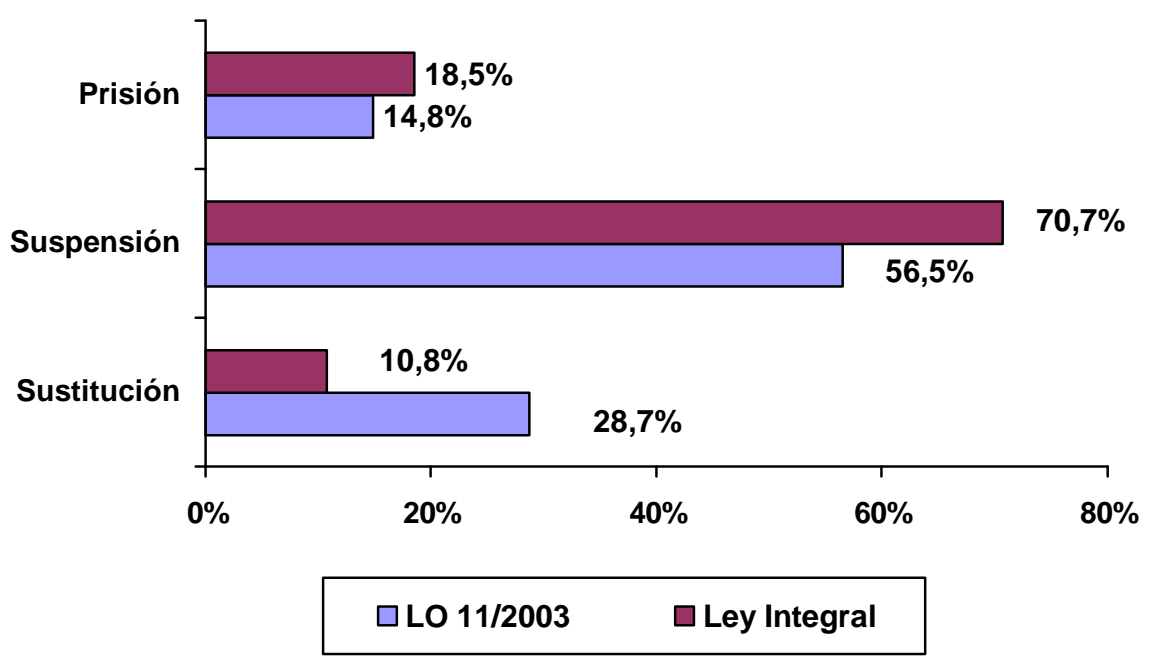

En la primera fase, con la aplicación de la LO 11/2003, del total de penas de prisión impuestas, en el 14,8\% de los casos la pena definitiva fue prisión, el 56,5\% suspensión y el $28,7 \%$ sustitución.

En la segunda fase, con la Ley Integral, respecto de las penas privativas de libertad impuestas, la pena definitiva fue en un $18,5 \%$ de los casos prisión, en un $70,7 \%$ suspensión y en un 10,8\% sustitución.

Podemos observar que con la Ley Integral aumenta el porcentaje de penas de prisión ejecutadas por la comisión de este delito. Debe advertirse no obstante que este aumento porcentual que se refleja en el gráfico de penas definitivas no implica una mayor entrada de personas en prisión, ya que el número total de penas de prisión impuestas es menor bajo la Ley Integral (véase gráfico 1). 
En cuanto al tiempo medio de las condenas a prisión definitivas, durante la aplicación de la LO 11/2003 fue de 7 meses y 25 días, mientras que con la Ley Integral fue de 8 meses y 21 días.

En segundo lugar, lo más destacado es el aumento de las suspensiones de la pena de prisión. Como puede verse en el gráfico 2, bajo la aplicación de la LO 11/2003 se concedió la suspensión de la pena en un $56,5 \%$ de los casos en los que se impuso la pena de prisión, mientras que con la Ley Integral este porcentaje aumenta a un $70,7 \%$. Una de las posibles explicaciones a este aumento es que bajo la Ley Integral la suspensiones van acompañadas necesariamente de la obligación a participar en un programa formativo o de tratamiento (art. 83.5 CP), lo que aumenta el castigo de las personas que ven suspendida la pena de prisión inicialmente impuesta.

De nuevo conviene recordar que, si bien la aplicación de las suspensiones aumenta bajo la Ley Integral, hay que tener en cuenta, tal y como ocurría en el caso de la prisión, que este aumento porcentual no se refleja en un aumento real del número total de suspensiones concedidas, ya que las penas de prisión impuestas son inferiores con la Ley Integral (véase gráfico 1).

Finalmente, por lo que respecta a la sustitución, observamos que bajo la Ley Integral se produce un importante descenso en su aplicación, ya que pasa de imponerse en un $28,7 \%$ de los casos bajo la LO 11/2003, a aplicarse un 10,8\% con la Ley Integral.

\subsection{Tipo de suspensión}

Respecto al tipo de suspensión que imponen los jueces, debe recordarse que existen dos posibilidades: la suspensión ordinaria, con la única condición de no volver a delinquir, y la suspensión con reglas de conducta, es decir, con la obligación de cumplir alguna de las condiciones recogidas en el art. $83 \mathrm{CP}$.

Hay que recordar también que a partir de la entrada en vigor de la LO 15/2003, la aplicación de la prohibición de acudir a determinados lugares (art. 83.1 CP) y de la prohibición de aproximación (art. 83.2 CP) pasó a ser obligatoria para la concesión de la suspensión. 
En consecuencia, debemos presentar los resultados en tres momentos diferentes: bajo la aplicación de la LO 11/2003, cuando la imposición de reglas de conducta era totalmente discrecional; bajo la aplicación de la LO 15/2003, cuando la imposición de las condiciones del art. 83.1 y 2 CP deviene obligatoria; y bajo la aplicación de la Ley Integral, que además de la imposición imperativa de las condiciones del art. 83.1 y 2 $\mathrm{CP}$, obliga a la imposición de la obligación de realizar programas formativos o de tratamiento (art. 83.5 CP).

En el siguiente gráfico podemos observar el porcentaje de casos en los que se aplica la suspensión ordinaria y en los que se aplica la suspensión con las reglas de conducta del art. $83 \mathrm{CP}$.

Gráfico 3: Porcentaje de aplicación de suspensiones ordinarias y con reglas de conducta

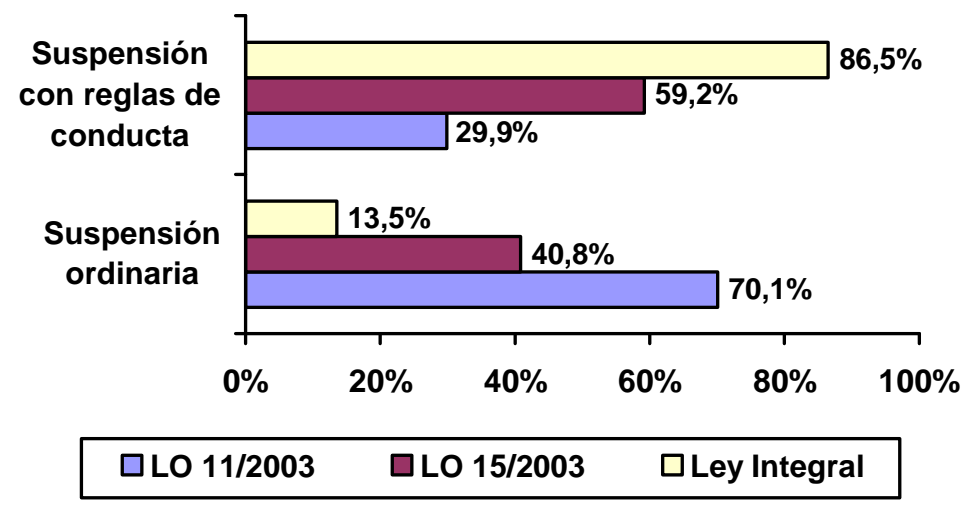

Podemos constatar que cada vez son mayores los casos en los que se imponen algún tipo de reglas de conducta, debido obviamente a la obligatoriedad impuesta por el legislador.

\subsection{Aplicación de la obligación de realizar programas formativos o de tratamiento (art. 83.5 CP).}

Por lo que respecta específicamente a la aplicación de la obligación de realizar programas formativos o de tratamiento como regla de conducta adicional a la suspensión, es conveniente realizar algunas aclaraciones previas a la presentación de los resultados. 
En el apartado anterior expusimos dos tipos de suspensión: ordinaria y con reglas de conducta (art. $83 \mathrm{CP}$ ). Dado que uno de nuestros objetivos es conocer el porcentaje de la obligación de realizar programas formativos como condición para la concesión de la suspensión (art. 83.5 CP), es imprescindible dividir la suspensión con reglas de conducta en dos tipos: las suspensiones concedidas con la obligación de realizar programas formativos y las que no obligan a la realización de este tipo de programas, pero sí al cumplimiento de otras condiciones reguladas en el art. $83 \mathrm{CP}$.

En la siguiente tabla podemos observar más claramente los distintos tipos de suspensión.

Tabla 2: Tipos de suspensión

\begin{tabular}{|c|l|}
\hline \multicolumn{1}{|c|}{ TIPOS DE SUSPENSIÓN } & \multicolumn{1}{|c|}{ DESCRIPCIÓN } \\
\hline Suspensión ordinaria & $\begin{array}{l}\text { Concesión de la suspensión bajo la única condición de no volver a } \\
\text { delinquir. }\end{array}$ \\
\hline $\begin{array}{l}\text { Suspensión con reglas de conducta } \\
\text { - Suspensión con condiciones } \\
\text { reguladas en el art. 83 CP (excepto } \\
\text { la obligación de realizar programas } \\
\text { formativos) }\end{array}$ & $\begin{array}{l}\text { Concesión de la prohibición de aproximación (art. 83.2 CP); prohibición de } \\
\text { ausentarse (art. 83.3 CP); obligación de comparecer ante el juez (art. } \\
83.4 \text { CP); obligación de cumplir determinados deberes (art. 83.6 } \\
\text { CP). }\end{array}$ \\
$\begin{array}{l}\text { Suspensión con programas alguna de las siguientes } \\
\text { formativos (art. 83.5 CP) }\end{array}$ & $\begin{array}{l}\text { Concesión de la suspensión bajo la obligación de realizar un } \\
\text { programa formativo o de tratamiento (también puede ir acompañada } \\
\text { de la obligación de cumplir alguna de las otras condiciones del art. } \\
83 \mathrm{CP})\end{array}$ \\
\hline
\end{tabular}

Una vez aclarados los diferentes tipos de suspensión que hemos diferenciado, presentaremos los resultados obtenidos en nuestro estudio respecto de la aplicación de la suspensión con la obligación de realizar programas formativos o tratamiento (art. 83.5 $\mathrm{CP})$. 
Gráfico 4: Aplicación de la obligación de realizar programas formativos o de tratamiento en casos de suspensión de la pena

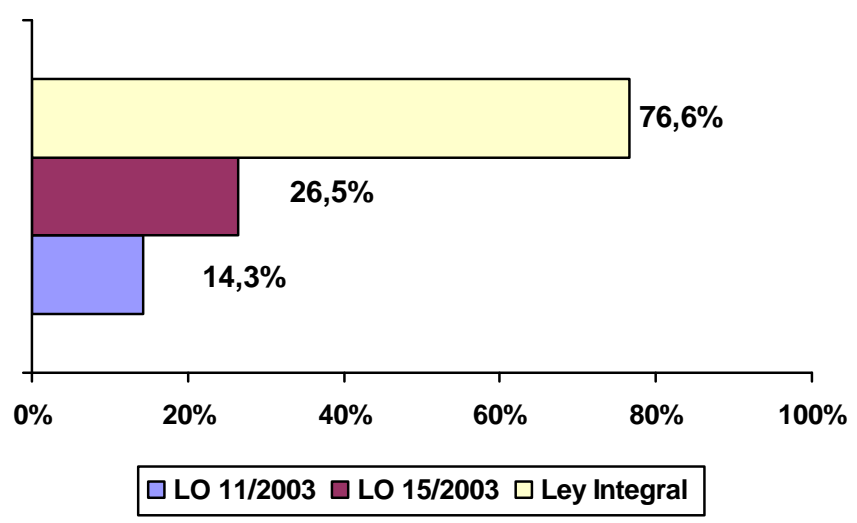

Según nuestros datos, con la LO 11/2003, cuando la aplicación del art. 83.5 CP era totalmente discrecional, éste se impuso en un $14,3 \%$. Con LO 15/2003, cuando la obligación de imponer esta regla de conducta seguía siendo discrecional, ésta se impuso en un $26,5 \%$ de los casos en los que se concedió la suspensión. Finalmente, con la aprobación de la Ley Integral, cuando su aplicación deviene obligatoria en casos de suspensión de la pena por violencia de género, se impone en un 76,6\% de los casos.

Evidentemente, este aumento obedece principalmente a su carácter obligatorio desde la aprobación de la Ley Integral, pero se debe observar que a pesar de no ser obligatoria su imposición en un principio, existe un aumento constante en su aplicación, como podemos ver en el gráfico 4.

\subsection{Penas definitivas}

Finalmente, como resumen global de la investigación realizada, presentamos en la siguiente tabla las penas definitivas que se están cumpliendo en Barcelona por la comisión de un delito de maltrato ocasional en el ámbito de la pareja durante el periodo comprendido entre 1 de octubre de 2003 y el 31 de diciembre de 2006, bajo la aplicación de la LO 11/2003 y de la Ley Integral (LO 1/2004): 
Tabla 3: Penas definitivas por maltrato ocasional en el ámbito de la pareja

\begin{tabular}{|c|c|c|c|c|}
\hline & LO & & $\overline{\text { LO }}$ & \\
\hline Penas definitivas por el art. $153 \mathrm{CP}$ & $\%$ & $\mathrm{~N}$ & $\%$ & $\mathrm{~N}$ \\
\hline Prisión & $12,2 \%$ & 33 & $10,4 \%$ & 29 \\
\hline Suspensión de la pena & $46,5 \%$ & 126 & $39,6 \%$ & 111 \\
\hline - Suspensión ordinaria & $27,3 \%$ & 74 & $5,3 \%$ & 15 \\
\hline - Suspensión con reglas de conducta & $19,2 \%$ & 52 & $34,3 \%$ & 96 \\
\hline $\begin{array}{l}\text { · Suspensión con programas formativos } \\
\text { (art. } 83.5 \mathrm{CP})\end{array}$ & $8,9 \%$ & 24 & $30,4 \%$ & 85 \\
\hline $\begin{array}{l}\text { - Suspensión con otras prohibiciones (art. } \\
83 \mathrm{CP} \text { ) }\end{array}$ & $10,3 \%$ & 28 & $3,9 \%$ & 11 \\
\hline TBC & $17,7 \%$ & 48 & $46,1 \%$ & 129 \\
\hline Multa & $22,1 \%$ & 60 & $1,1 \%$ & 3 \\
\hline Expulsión & $1,5 \%$ & 4 & $2,9 \%$ & 8 \\
\hline Total & $100 \%$ & 271 & $100 \%$ & 280 \\
\hline
\end{tabular}

A continuación, en el último apartado de discusión, presentaremos una serie de reflexiones que explican esta tabla de penas definitivas.

\section{Discusión}

La ley que supuso un mayor impacto en lo que respecta a penas impuestas fue la LO 11/2003, que posibilitó la aplicación de la pena de prisión para este delito. Esta iniciativa legislativa se vio respaldada por los jueces, quienes aplicaron la pena privativa de libertad en un $82,6 \%$ de los casos (véase gráfico 1), a pesar de contar con el trabajo en beneficio de la comunidad como pena principal opcional y también desoyendo las indicaciones del Tribunal Constitucional conforme la pena de prisión se reservaría para los casos de maltrato grave. Una cuestión a destacar negativamente es que, aun tratándose de los supuestos más leves de violencia, los jueces aplican mayoritariamente la pena de prisión y sólo en un 17,4\% la pena de TBC. 
La Ley Integral ha conllevado, respecto de la LO 11/2003, una menor imposición de penas de prisión (gráfico 1). Como ya apuntamos, queda como paradoja que los cambios introducidos por la Ley Integral destinados en principio a aumentar la severidad de la respuesta penal han conllevado una menor imposición de penas de prisión a los supuestos de violencia ocasional en las relaciones de pareja.

No obstante esta conclusión debe matizarse, pues como ya hemos comentado, el tiempo medio de condena de las pena de prisión impuestas es mayor bajo la Ley Integral ( 7 meses y 27 días) que bajo la LO 11/2003 (6 meses y 2 días). En consecuencia, se imponen menos penas de prisión pero estas son de una cierta mayor duración.

Una vez aprobada la Ley Integral, el aspecto sin duda más destacado es el aumento en la imposición del TBC. En parte, la reducción que experimenta la imposición de la pena de prisión se debe a que los jueces han empezado a optar de forma más decidida por la pena de TBC, la cual ya estaba prevista en la LO 11/2003.

El mayor uso de esta pena podría obedecer a los siguientes motivos. Por un lado, debido a la ausencia de alternativas, pues se elimina la posibilidad de la pena principal de multa, y existe quizás una cierta reticencia de que la prisión constituya una respuesta proporcional y adecuada a todos los casos leves de violencia de género.

Por otro lado, no puede descartarse una mayor familiaridad y una mayor confianza de la judicatura con el TBC, sobre todo tras la aprobación de la LO 15/2003, en la que se recoge una mejor regulación de la pena de TBC (Blay, 2007), y un mayor esfuerzo por parte de la Administración.

Además, la Ley Integral impidió en casos de violencia de género la sustitución de la pena de prisión por multa y estableció como única posibilidad la sustitución de prisión por TBC. Esta obligatoriedad explica el aumento de imposición de esta sanción como pena principal, ya que hacerlo por vía de la sustitución para finalmente aplicar la misma pena, duplica el trabajo de los jueces y además da lugar a condenas demasiado largas, 
debido al cómputo establecido para la sustitución, que supone el cumplimiento de un día de TBC por cada día de prisión impuesto (Blay, comunicación personal).

En esta línea con la LO 11/2003 la sustitución se aplica en un 28,7\%\%, mientras que con la Ley Integral este porcentaje disminuye hasta el 10,8\% (gráfico 2). Una de las razones por las que se produce este descenso en las sustituciones es probablemente como ya hemos mencionado, que la Ley Integral impide sustituir la pena de prisión por multa, de manera que los jueces que antes imponían una pena de prisión para acabar sustituyéndola por multa se ven privados de esta opción.

Otro motivo probable por el cual disminuye la sustitución de la pena de prisión es que durante la aplicación de la LO 11/2003 son posibles condenas de menos de tres meses que se sustituyen de acuerdo al artículo $71.2 \mathrm{CP}$ de forma automática por multa, sin embargo, con la aplicación de la Ley Integral, al haber aumentado el tiempo mínimo de condena a seis meses, esta sustitución automática ya no es posible.

Por lo que respecta a la suspensión de la pena, lo más remarcable es la reducción en el uso de la suspensión ordinaria ( 5,3\%. La imposición de condiciones para la concesión de la suspensión implica materializar la idea de que las penas deben tener como objetivo no sólo el castigo de la persona que delinque sino además la 'protección de la víctima', el cual pasa a ser defendido como un objetivo que la pena debe cumplir (Cid-Larrauri, 2005)

Es también importante el aumento continuo de la aplicación de la obligación de realizar programas formativos o de tratamiento como condición para la suspensión que pasa de estar representada en el conjunto de penas definitivas de un $8,9 \%$ a un $30,4 \%$. Este aumento refleja varios fenómenos. Por un lado, es quizás indicativo de la creciente confianza de los jueces en esta medida rehabilitadora, quienes, aunque no de forma unánime, sí tienden a aplicarlo de forma mayoritaria (véase gráfico 4). Por otro lado, refleja probablemente la convicción del legislador de que la suspensión de la condena sin otra regla de conducta adicional puede verse como un castigo escaso en tiempos en los que se reclama que también las penas no privativas de libertad tengan una carga punitiva (Larrauri, 2005b). Todo ello conlleva finalmente que la actual suspensión de la

Revista Española de Investigación Criminológica 
condena de prisión se asimile más a una pena de probation que a la suspensión de la condena tradicional en España (Cid, 2009).

Finalmente, podemos ver que la aplicación de la multa se reduce en el segundo periodo hasta prácticamente desaparecer. Ello obedece en parte a las críticas de que ha sido objeto esta pena en el ámbito de la violencia de género ${ }^{15}$. Recordemos que en la LO 11/2003, el legislador la elimina como pena principal opcional, y únicamente permite su aplicación por vía de sustitución. Con la aprobación de la Ley Integral desaparece además como pena sustitutiva, ya que las penas de prisión impuestas por delitos de violencia de género únicamente se pueden sustituir por TBC. El hecho de que bajo la LO 11/2003 la pena de prisión fuese sustituida por multa en un $22,1 \%$ de los casos permite especular que, a pesar de las críticas de algunos grupos feministas y de una parte de la doctrina, esta pena sí es considerada una respuesta adecuada para determinados supuestos leves de violencia de género.

Esperamos por último que esta investigación sirva para estimular, por lo menos, dos futuras pesquisas. La primera debería intentar averiguar quienes son las personas que entran en prisión por un delito de maltrato ocasional, que, independientemente de su gravedad moral, no amerita una respuesta penal tan severa. Así, en cada periodo analizado, de un total de 275 condenados, aproximadamente 32 entraron en prisión por la comisión de un delito de maltrato ocasional en el ámbito de la pareja, consistente en empujones, gritos, o insultos.

La segunda, debería intentar comprobar la eficacia de otro tipo de respuestas distintas a la prisión que ya hoy constituyen la respuesta penal mayoritaria a los casos leves de violencia de género.

\footnotetext{
${ }^{15}$ Señalamos 'en parte' porque el descenso de la multa es un fenómeno general en otros países europeos y no limitado al ámbito de la violencia de género. Ello puede obedecer a que en general se considera esta sanción poco punitiva o poco intervencionista en momentos en los que se demanda más al sistema penal que una sola sanción económica (Larrauri,2005b)
}

Revista Española de Investigación Criminológica 


\section{Referencias}

Alberdi, I., Matas, N. (2002). La violencia doméstica: informe sobre los malos tratos a mujeres en España. Colección Estudios Sociales, núm. 10. Fundación "La Caixa".

Antón, L. (2008). Evaluación de la aplicación judicial del delito de maltrato ocasional (art. 153 CP): su transformación de falta a delito: LO 11/2003. Tesina de doctorado. UAB. No publicada.

Arroyo, A., Muñoz Cuesta, J. (1993): El delito de lesiones. Pamplona: Aranzadi.

Asúa, A. (2004). Los nuevos delitos de 'violencia doméstica' tras la reforma de la LO 11/2003 de 29 de septiembre. En Cuadernos Penales José María Lidón, nº 1. Bilbao: Universidad de Deusto.

Benítez, M.J. (2004). Violencia contra la mujer en el ámbito familiar, cambios sociales y legislativos. Madrid: Edisofer.

Blay, E. (2007). El trabajo en beneficio de la comunidad. Barcelona: Atelier.

Calvo, M. (2003): El tratamiento de la violencia doméstica en la Administración de Justicia. Madrid: Consejo General del Poder Judicial.

Calvo, M. (2004). La respuesta desde las instituciones y el derecho frente al problema de la violencia doméstica en Aragón. Madrid: Dykinson.

Calvo, M. (2005). Evolución de la respuesta jurídica frente a la violencia familiar de género. Análisis de la LO 1/2204, de Medidas de Protección Integral contra la Violencia de Género. En Cuadernos penales, José María Lidón, no 2. Bilbao: Universidad de Deusto.

Cervelló, V. (1994). El delito de malos tratos: su delimitación con el derecho de corrección. En Poder Judicial, pp. 45-67.

Cid, J. (2009). La elección del castigo. Barcelona: Bosch.

Cid, J, Larrauri, E. et al. (2002). Jueces penales y penas en España. (aplicación de las penas alternativas a la privación de libertad en los juzgados de lo penal). Valencia: Tirant lo Blanch.

Cid, J, Larrauri, E. (2005): Evolución de las penas alternativas. En Cid, J., Larrauri, E. (coords.) La delincuencia violenta: ¿prevenir, castigar o rehabilitar? Valencia. Tirant lo Blanch.

Revista Española de Investigación Criminológica

Artículo 2, Número 7 (2009) $\quad$ www.criminología.net

ISSN: $1696-9219$ 
Comas, M. (2002). El País, 6 de diciembre de 2002.

http://www.elpais.com/articulo/sociedad/faltas/mujer/seran/delitos/elpepisoc/20021206e lpepisoc 2/Tes

Comas, M. (2005). Poder judicial y violencia doméstica, ¿qué hemos logrado? ¿qué debemos lograr?. En Cuadernos de Derecho Judicial. La violencia doméstica: enfoque en España y en el derecho comparado. Madrid: Consejo General del Poder Judicial.

Consejo General del Poder Judicial. (2001). Informe del Pleno, de 21 de marzo de 2001, sobre la problemática jurídica derivada de la violencia doméstica: http://www.fiscalia.org/doctdocu/docu/cgpjvioldomest.pdf

Cortés, E. (2000). El delito de malos tratos familiares: nueva regulación. Barcelona/Madrid: Marcial Pons.

Cuello, J. (1993). El delito de violencia habitual en el seno de la familia y otras relaciones análogas de afectividad. En Poder Judicial, pp. 9-18.

Defensor del Pueblo. (1998). La violencia doméstica contra las mujeres.

http://www.defensordelpueblo.es/index.asp?destino=informes2.asp

Delgado, J. (2001). La violencia doméstica. Tratamiento jurídico: problemas penales y procesales; la jurisdicción civil. Colex.

Falcón, L. (1991). Violencia contra la mujer. Barcelona: Círculo de lectores.

Informe de la Comisión de Relaciones con el Defensor del Pueblo y de los Derechos Humanos encargada del estudio de la mujer maltratada. Bocg, Senado, III Legislatura, serie I: Boletín General, 12 de mayo de 1989, nº 313.

http://www.senado.es/legis3/publicaciones/pdf/senado/bocg/I0313.PDF

Instituto de la Mujer. (1990): Situación social de las mujeres en España.

Instituto de la Mujer. (2006): III Macroencuesta sobre la violencia contra las mujeres.

Sigma Dos. Ministerio de Trabajo y Asuntos sociales, Secretaría General de Políticas de Igualdad

Larrauri, E. (2004). ¿Es posible el tratamiento de los agresores de violencia doméstica?. En Zugaldía, J.M., López, J. (coords): Dogmática y ley penal. Libro homenaje a Enrique Bacigalupo. Volumen I. Madrid: Marcial Pons.

Larrauri, E. (2005a): ¿Se debe proteger a la mujer contra su voluntad?. En Cuadernos penales José $M^{a}$ Lidón, $\mathrm{n}^{\circ}$ 2. Bilbao: Universidad de Deusto. 
Larrauri, E. (2005b). Populismo punitivo y penas alternativas a la prisión. En Bacigalupo, S., Cancio, M. (coords): Derecho penal y política transnacional. Barcelona, Atelier.

Larrauri, E. (2007). Criminología Crítica y Violencia de Género. Madrid: Trotta.

Larrauri, E. (2009). Igualdad y violencia de género: comentario a la STC 59/2008. En Indret, $\mathrm{n}^{\mathrm{o}} 1$.

Laurenzo, P. (2003). Los nuevos delitos de violencia doméstica: otra reforma precipitada. En Artículo 14. Sevilla: Instituto Andaluz de la Mujer.

Magro, V. (2005). Soluciones de la sociedad española ante la violencia que se ejerce sobre las mujeres. Madrid: La Ley.

Medina, J.J. (2002). Violencia contra la mujer en la pareja: investigación comparada y situación en España. Valencia: Tirant lo Blanch.

Morillas, L. (2002). Respuestas del código penal ante la violencia doméstica. Propuestas de reforma. En Morillas, L.: Estudios penales sobre violencia doméstica. http://www.vlex.com/vid/298599

Observatorio estatal de violencia sobre la mujer. Informe Anual:

http://www.el-refugioesjo.net/maltrato/informe-anual-observarorio.pdf

Peñaranda (2008). Qué puede hacer el derecho penal contra la violencia de género?. En Debate, Facultad de derecho, UAM (numero 2).

Themis, Asociación de Mujeres Juristas. (1999). Respuesta penal a la violencia familiar. Estudio sobre el tratamiento judicial de los procedimientos seguidos por malos tratos a las mujeres en el ámbito doméstico en la comunidad de Madrid. Madrid: Consejo de la Mujer de la Comunidad de Madrid.

Themis, Asociación de Mujeres Juristas. (2001). Réplica al Informe del CGPJ sobre la problemática jurídica derivada de la violencia doméstica.

www.nodo50.org/mujeresred/violencia-contra_informe.html\#a

Themis, Asociación de Mujeres Juristas. (2003). La violencia Familiar en el ámbito judicial. Madrid: Junta de Comunidades de Castilla La Mancha. 


\section{Agradecimientos}

Este artículo constituyó la tesina de doctorado de Lorena Antón (UAB, 15/09/2008). Se integra dentro del proyecto de investigación 'Políticas de reinserción en el ámbito penal' (DER2008-05041/JURI, Ministerio de Ciencia e Innovación), y dentro del Grupo Consolidado de 'Criminología aplicada a la penología' (SGR-08024, Generalitat de Cataluña, AGAUR). Además, se ha contado con una subvención del Institut Català de les Dones (U-27/06) y del Centre d'Estudis Jurídics i Formació Especialitzada (JUS/3967/2007). Agradecemos la colaboración de Aina Ibáñez, y Patricia Martín así como la discusión con los miembros del grupo de investigación del cual formamos parte, y en particular las correcciones hechas por Ester Blay. También agradecemos las observaciones realizadas por los evaluadores anónimos de la REIC. 